"This is the peer reviewed version of the following article: [Dalton Trans., 2019, 48, 10853] which has been published in final form at [Link to final article using the DOI: 10.1039/c9dt00530grsc.li/dalton]. This article may be used for non-commercial purposes in accordance with the Royal Society of Chemistry Terms and Conditions for Self-Archiving."

\title{
ARTICLE
}

Received 00th January 20xx, Accepted 00th January 20xx DOI: $10.1039 / x 0 \times x 00000 x$

\section{A Complete Series of Uranium(IV) Complexes with Terminal Hydrochalcogenido (EH) and Chalcogenido (E) Ligands $E=0, S$, Se, Te}

Michael W. Rosenzweig, ${ }^{a}$ Julian Hümmer, ${ }^{a}$ Andreas Scheurer, ${ }^{a}$ Carlos Alvarez Lamsfus, ${ }^{\text {b }}$ Frank W. Heinemann, ${ }^{a}$ Laurent Maron, ${ }^{\mathrm{b}}$ Marinella Mazzanti, ${ }^{\mathrm{c}}$ and Karsten Meyer ${ }^{\mathrm{a} *}$

\begin{abstract}
We here report the synthesis and characterization of a complete series of terminal hydrochalcogenido, U-EH, and chalcogenido uranium(IV) complexes, $\mathrm{U} \equiv \mathrm{E}$ (with $\mathrm{E}=\mathrm{O}, \mathrm{S}, \mathrm{Se}, \mathrm{Te})$, supported by the $\left({ }^{\mathrm{Ad}, \mathrm{Me}} \mathrm{ArOH}\right) 3 \operatorname{tacn}(1,4,7$-tris(3-(1-adamantyl)-5methyl-2-hydroxybenzyl)-1,4,7-triazacyclononane)) ligand system. Reaction of $\mathrm{H}_{2} \mathrm{E}$ with the trivalent precursor $\left[\left(\left({ }^{\mathrm{Ad}, \mathrm{Me}} \mathrm{ArO}\right)_{3} \mathrm{tacn}\right) \mathrm{U}\right](\mathbf{1})$ yields the corresponding uranium(IV) hydrochalcogenido complexes [(( $\left.\left.\left.{ }^{\mathrm{Ad}, \mathrm{Me}} \mathrm{ArO}\right)_{3} \mathrm{tacn}\right) \mathrm{U}(\mathrm{EH})\right]$ (2). Subsequent deprotonation of the terminal hydrochalcogenido species with $\mathrm{KN}\left(\mathrm{SiMe}_{3}\right)_{2}$, in the presence of 2.2.2-cryptand, gives access to the uranium(IV) complexes with terminal chalcogenido ligands [K(2.2.2-crypt)][((Ad,Me $\left.\left.\mathrm{ArO}){ }_{3} \operatorname{tacn}\right) \mathrm{U} \equiv \mathrm{E}\right](3)$. In order to study the influence of the varying terminal chalogenido ligands on the overall molecular and electronic structure, all complexes were studied by single-crystal X-ray diffractometry, UV/vis/NIR, electronic absorption, and IR vibrational spectroscopy as well as SQUID magnetometry and computational analyses (DFT, MO, NBO).
\end{abstract}

\section{Introduction}

Transition metal chalcogenido species represent an important class of compounds in the field of coordination and solid-state chemistry. This is due to applications in chemical catalysis and materials science, and were found to be relevant intermediates in bioinorganic chemistry. ${ }^{1-15}$ Interest in chalcogenido lanthanide and actinide coordination chemistry also stems from separation and remediation research, employing sulfur-containing chelating ligands. ${ }^{16-20}$ The separation chemistry relies on the distinct and highly specific coordination affinity of the $f$-elements to chalcogenido ligands, which often

\footnotetext{
a. Department of Chemistry and Pharmacy, Inorganic Chemistry, FriedrichAlexander University Erlangen-Nürnberg, Egerlandstraße 1, 91058 Erlangen.

b. LPCNO, Université de Toulouse, INSA Toulouse, 135 Avenue de Rangueil, 31077 Toulouse, France.

c. Institut des Sciences et Ingénierie Chimiques, Ecole Polytechnique Fédérale de Lausanne (EPFL), 1015 Lausanne, Switzerland.

†Electronic Supplementary Information (ESI) available: [details of any supplementary information available should be included here]. See DOI: $10.1039 / x 0 x \times 00000 x$
}

is attributed to the various degrees of covalency within the $4 f / 5 f$ metal-ligand bonds. Accordingly, and fostered by everincreasing computational resources, the nature of the actinidechalcogen bond has become a topic of growing current interest. ${ }^{21-24}$ In the last decade, the exploration of uraniumligand multiple bonding was driven by the synthesis of challenging target and trophy molecules such as uranium carbene, ${ }^{25-30}$ pnictide (pnictinidene $(\mathrm{NH}, \mathrm{PH}, \mathrm{AsH}), 31,33,40-41$ pnictido $(\mathrm{N}, \mathrm{As})^{34}$, ${ }^{42}$ ), hydrochalcogenido ( $\left.\mathrm{SH}, \mathrm{SeH}, \mathrm{TeH}\right),{ }^{22}$ and chalcogenido (S, $\mathrm{Se}, \mathrm{Te})^{35-37,39}$ species. Complexes containing the lighter homologues are more common, and thus, numerous $\mathrm{U}-\mathrm{N}$ and $\mathrm{U}-\mathrm{O}$ compounds are known, whereas heavier pnictide and chalcogenide uranium representatives are rare. ${ }^{38}$ In-depth DFT calculations and analyses of $\mathrm{U}-\mathrm{E}$ multiple bonds revealed a significant degree of covalency. The bonds are often strongly polarized towards the terminal ligand, and the bonding orbitals predominantly consist of $6 d / 5 f$ hybrid orbitals. ${ }^{23-24,38}$

In order to gain a more systematic insight into these uranium-chalgogenide multiple bonds, the synthesis of a complete series of complexes, bearing varying terminal ligands of one 
specific group provides a useful series of species for comprehensive spectroscopic studies. Importantly, an identical ancillary ligand system throughout the series is required to exclude effects of the supporting ligand. Following this strategy, the group of Hayton synthesized a series of uranium(IV) complexes with the terminal chalcogenido ligands (O, S, Se, Te), employing the original, trivalent uranium trisamide precursor, $\left[\mathrm{U}\left(\mathrm{N}\left(\mathrm{SiMe}_{3}\right)_{2}\right)_{3}\right]$, and the elemental chalcogens. ${ }^{35}$

Previously, our group has reported the first series of uranium(IV) complexes with terminal hydrochalcogenides $(\mathrm{EH}=\mathrm{SH}$, $\mathrm{SeH}, \mathrm{TeH})$, stabilized by the $\mathrm{N}$-anchored ancillary system $\left.(\mathrm{Ad}, \mathrm{Me} \mathrm{ArOH})_{3} \mathrm{~N}\right) \quad$ (= tris(2-hydroxy-(3-adamant-3-yl)-5-methylbenzyl)amine). ${ }^{22}$ However, attempts to synthesize the terminal chalcogenido species mainly led to dimerization with bridging chalcogenido or polychalcogenido ligands. This is likely due to the chelate's high flexibility and lack of steric bulk around the reactive terminal ligand. ${ }^{43,44}$ We have shown in the past, that a reactive terminal ligand is stabilized by the use of sterically very demanding supporting ligand systems; thereby, preventing undesired side and dinuclear decomposition reactions (e.g. dimerization). ${ }^{46-47}$ For example, a terminal hydrosulfido as well as sulfido UIV complex can be synthesized starting from the trivalent uranium precursor [(( $\left.\left.\mathrm{Ad}, \mathrm{Me} \mathrm{ArO})_{3} \mathrm{tacn}\right) \mathrm{U}\right](\mathbf{1})$, supported by the sterically highly demanding and rigid ( $\mathrm{Ad}, \mathrm{Me} \mathrm{ArOH})_{3}$ tacn (= 1,4,7-tris(3-(1-adamantyl)-5-methyl-2-hydroxybenzyl)-1,4,7triazacyclononane)) ligand system. ${ }^{24}$

With the recently reported pair of complexes [(( $\left.\mathrm{Ad}, \mathrm{Me} A \mathrm{ArO})_{3} \mathrm{tacn}\right)-$ $\left.\mathrm{U}^{\mathrm{IV}}(\mathrm{SH})\right](\mathbf{2}-\mathrm{SH})$ and $\left[\left(\left({ }^{\mathrm{Ad}, \mathrm{Me}} \mathrm{ArO}\right)_{3} \operatorname{tacn}\right) \mathrm{U}^{\mathrm{IV}}(\mathrm{S})\right]^{-}(\mathbf{3} \equiv \mathbf{S})^{-}$, we have continued our efforts to synthesize the first complete series of uranium coordination complexes with terminal hydrochalcogenido and chalcogenido ligands on a single supporting ligand platform, namely ( $\mathrm{Ad}, \mathrm{Me} A \mathrm{ArO})_{3} \mathrm{tacn}^{3-}$, and herein present the synthesis and characterization of the comprehensive series of eight uranium(IV) complexes with terminal Group 16 ligands $\mathrm{OH}, \mathrm{SH}, \mathrm{SeH}$, and $\mathrm{TeH}$ as well as $\mathrm{O}, \mathrm{S}, \mathrm{Se}$, and $\mathrm{Te}$. 


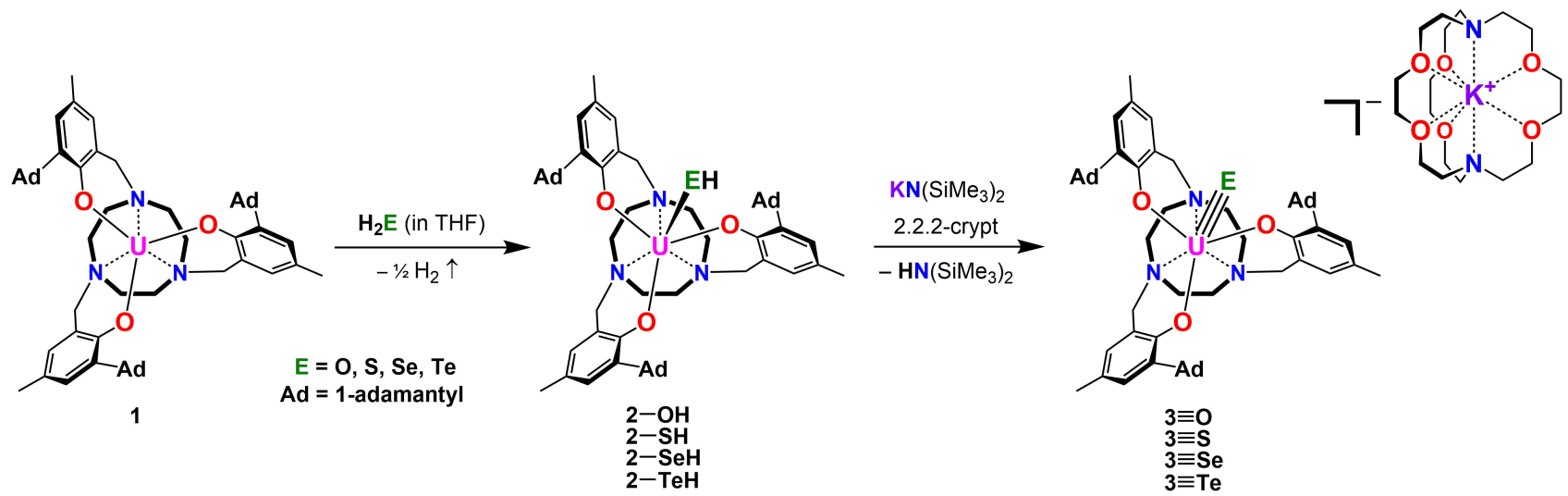

Scheme 1: Synthetic route to the terminal uranium(IV) hydrochalcogenido and chalcogenido complexes 2 and $\mathbf{3}$.
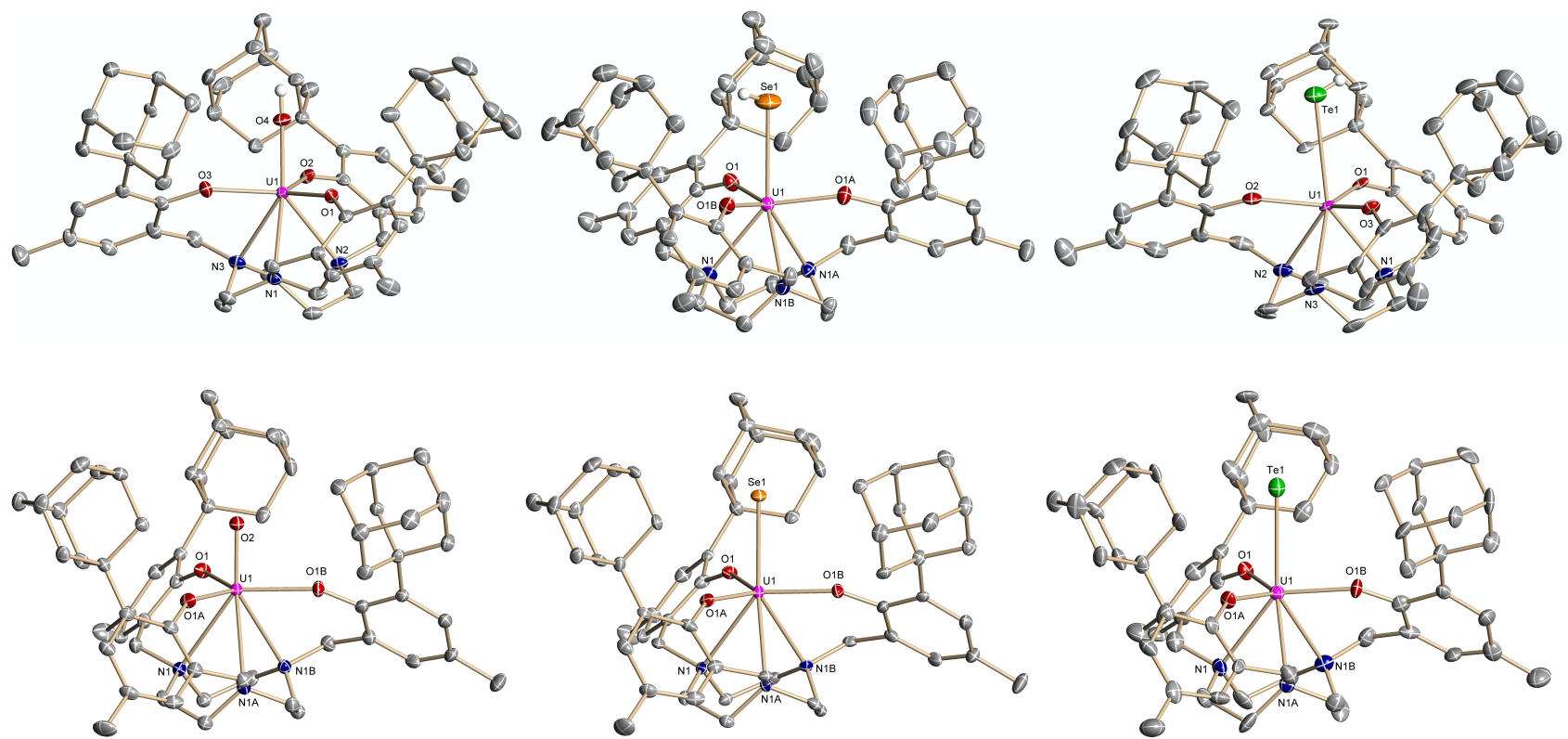

Fig. 1: Solid state structures of 2-OH (top, left) in crystals of [((Ad,MeArO) $\left.\left.{ }_{3} \operatorname{tacn}\right) \mathrm{U}(\mathrm{OH})\right] \cdot 2 \mathrm{THF}$, 2-SeH (top, middle) in crystals of $\left[\left(\left({ }^{\mathrm{Ad}, \mathrm{Me}} \mathrm{ArO}\right)_{3} \mathrm{tacn}\right) \mathrm{U}(\mathrm{SeH})\right] \cdot 2.25 \mathrm{THF}, 2-\mathrm{TeH}$ (top, right) in crystals of $\left[\left(\left(\mathrm{Ad}^{\mathrm{Ae}} \mathrm{ArO}\right)_{3} \mathrm{tacn}\right) \mathrm{U}(\mathrm{TeH})\right] \cdot 3 \mathrm{CH}_{2} \mathrm{Cl}_{2}$, and molecular representations of complex anions $\mathbf{3} \equiv \mathbf{0}$ (bottom left), in crystals of [K(2.2.2-crypt][((Ad,Me $\left.\left.\mathrm{ArO})_{3} \operatorname{tacn}\right) \mathrm{U}(\mathrm{O})\right], \mathbf{3} \equiv \mathrm{Se}$ (bottom, middle) in crystals of [K(2.2.2crypt][((Ad,MeArO) ${ }_{3}$ tacn) $\left.\mathrm{U}(\mathrm{Se})\right]$, and $\mathbf{3} \equiv \mathrm{Te}$ (bottom, right) in crystals of [K(2.2.2-crypt][(( $\left.{ }^{\mathrm{Ad}, \mathrm{Me} A \mathrm{ArO}}\right)_{3}$ tacn) $\left.\mathrm{U}(\mathrm{Te})\right]$. The sulfur analogs $\left[\left(\left({ }^{\mathrm{Ad}, \mathrm{Me}} \mathrm{ArO}\right)_{3} \mathrm{tacn}\right) \mathrm{U}(\mathrm{SH})\right]$ and $\left[\left(\left(\mathrm{Ad}^{\mathrm{A}} \mathrm{Me} \mathrm{ArO}\right)_{3} \mathrm{tacn}\right) \mathrm{U}(\mathrm{S})\right]$ were reported elsewhere. ${ }^{24}$ The complex cations $\left[\mathrm{K}\left(2.2 .2 . \text {-crypt }^{2}\right]^{+}, \mathrm{H}-\mathrm{atoms}(\mathrm{except}\right.$ for $\mathrm{EH})$, and co-crystallized solvents are omitted for clarity; thermal ellipsoids are at $50 \%$ probability.

Table 1: Selected bond lengths ( $(\AA)$ and angles (deg) for complexes $\mathbf{2}-\mathbf{O H}, \mathbf{2}-\mathbf{S H}, \mathbf{2}-\mathrm{SeH}$, and $\mathbf{2}-\mathrm{TeH}$ as well as $\mathbf{3} \equiv \mathbf{0}, \mathbf{3} \equiv \mathbf{S}, \mathbf{3} \equiv \mathrm{Se}$, and $\mathbf{3} \equiv \mathrm{Te}$. Values for $\mathbf{2}-\mathbf{S H}$ and $\mathbf{3} \equiv \mathbf{S}$ were taken from ref. 24. The $\mathrm{U}-\mathrm{O}-\mathrm{H}$ and $\mathrm{U}-\mathrm{S}-\mathrm{H}$ bond angles were determined with the located and refined $\mathrm{H}$ positions taken from the difference Fourier map. The $\mathrm{U}-\mathrm{E}-\mathrm{H}$ angles $(\mathrm{E}=\mathrm{Se}, \mathrm{Te})$ were determined with $\mathrm{H}$ atoms in calculated positions. 2SH and 2-SeH crystallize with two independent molecules in the asymmetric unit. a) The ionic radii sum was calculated from the effective ionic radii listed in ref. 48.

\begin{tabular}{|l|c|c|c|c|c|c|c|c|}
\hline & $2-\mathrm{OH}$ & $2-\mathrm{SH}$ & $2-\mathrm{SeH}$ & $2-\mathrm{TeH}$ & $3 \equiv 0$ & $3 \equiv \mathrm{S}$ & $3 \equiv \mathrm{Se}$ & $3 \equiv \mathrm{Te}$ \\
\hline $\mathrm{U}-\mathrm{E}$ & $2.079(3)$ & $\begin{array}{c}2.844(4) / \\
2.775(2)\end{array}$ & $\begin{array}{c}2.916(2) / \\
2.901(2)\end{array}$ & $3.173(1)$ & $1.868(5)$ & $2.536(2)$ & $2.695(2)$ & $2.942(2)$ \\
\hline $\begin{array}{l}\text { Sum of ionic } \\
\text { radii a) }\end{array}$ & 2.30 & 2.79 & 2.93 & 3.16 & 2.30 & 2.79 & 2.93 & 3.16 \\
\hline $\mathrm{U}-\mathrm{O}_{\mathrm{Ar}}(\mathrm{av})$ & 2.197 & $2.152 / 2.188$ & $2.164 / 2.173$ & 2.165 & 2.283 & 2.222 & 2.213 & 2.204 \\
\hline
\end{tabular}




\begin{tabular}{|l|c|c|c|c|c|c|c|c|}
\hline U-N $\mathrm{N}_{\text {tacn }}(\mathrm{av})$ & 2.721 & $2.680 / 2.650$ & $2.662 / 2.629$ & 2.644 & 2.929 & 2.848 & 2.811 & 2.767 \\
\hline $\mathrm{U}_{\text {oop }}$ & $-0.156(2)$ & $\begin{array}{c}-0.268(5) / \\
-0.282(4)\end{array}$ & $\begin{array}{c}-0.273(7) / \\
-0.306(7)\end{array}$ & $-0.278(3)$ & $-0.082(5)$ & $-0.086(7)$ & $-0.117(8)$ & $-0.181(16)$ \\
\hline$\Varangle \mathrm{U}-\mathrm{E}-\mathrm{H}$ & $175(4)$ & $152 / 156$ & $109 / 109$ & 109 & & & & \\
\hline
\end{tabular}

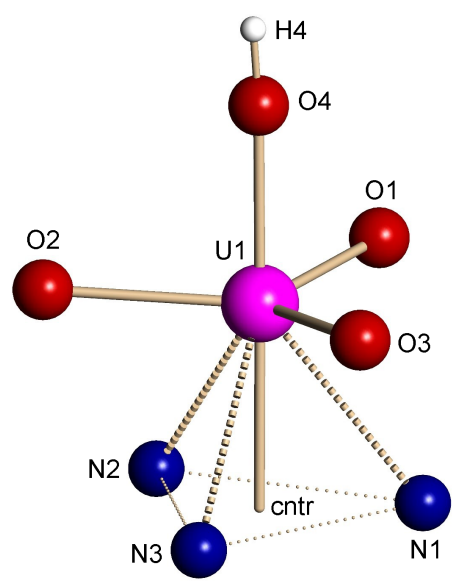

Fig. 2: Schematic representation of the complexes' capped trigonal bipyramidal geometry. The O4-U1-cntr angle in 2-OH has been

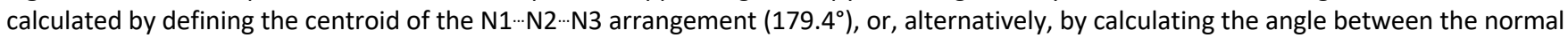
of the $\mathrm{N} 1 \cdots \mathrm{N} 2 \cdots \mathrm{N} 3$ least-squares plane and the $\mathrm{U} 1-\mathrm{O} 4$ vector $\left(1.4^{\circ}\right.$ and a resulting $\mathrm{O} 4-\mathrm{U} 1-\mathrm{cntr}$ angle of $\left.178.6^{\circ}\right)$. For $3 \equiv \mathrm{E}$, these angles equal $180^{\circ}$ due to the threefold crystallographic rotation axis. 
"This is the peer reviewed version of the following article: [Dalton Trans., 2019, 48, 10853] which has been published in final form at [Link to final article using the DOI: 10.1039/c9dt00530grsc.li/dalton]. This article may be used for non-commercial purposes in accordance with the Royal Society of Chemistry Terms and Conditions for Self-Archiving."

\section{ARTICLE}

\section{Results and Discussion}

Synthesis and molecular structures of the terminal uranium(IV) hydrochalcogenido and chalcogenido complexes

To synthesize the terminal hydrochalcogenido complexes, trivalent uranium complex [((Ad,Me $\left.\left.\mathrm{ArO})_{3} \mathrm{tacn}\right) \mathrm{U}\right](\mathbf{1})$ was treated with solutions of $\mathrm{H}_{2} \mathrm{E}(\mathrm{E}=\mathrm{O}, \mathrm{S}, \mathrm{Se}, \mathrm{Te})$ in $\mathrm{THF}$ to form [(( $\left.\left.\left.{ }^{\mathrm{Ad}, \mathrm{Me}} \mathrm{ArO}\right)_{3} \mathrm{tacn}\right) \mathrm{U}-\mathrm{EH}\right](\mathrm{E}=\mathrm{O}, \mathbf{2}-\mathrm{OH} ; \mathrm{E}=\mathrm{S}, \mathbf{2}-\mathrm{SH} ; \mathrm{E}=\mathrm{Se}, \mathbf{2}-\mathrm{SeH}$; $E=T e, 2-T e H)$ with concomitant evolution of $1 / 2$ equiv. of dihydrogen gas (Scheme 1). It ought to be mentioned that, due to the high oxophilicity, the remarkable reducing power of trivalent uranium species, and the preference of uranium ions to bind multiple bonded oxido ligands, mononuclear uranium complexes with terminal hydroxido ligands are rare. Their straight-forward, controlled synthesis usually requires a sterically exceedingly demanding and rigid ligand. ${ }^{47}$ Investigation of the molecular structures revealed all hydrochalcogenide complexes to be isostructural, featuring a seven-coordinate uranium ion in a capped trigonal bipyramidal coordination environment, with the $\mathrm{EH}^{-}$ligand occupying the axial position trans to the triazacyclononane anchor (Fig. 1, top, and Fig. 2). Complex 2-OH crystallizes in a triclinic, centrosymmetric space group $P \overline{1}$, whereas $\mathbf{2}$-SH and $\mathbf{2}$-SeH crystallize in the chiral, hexagonal space group $P 6_{3}$, with two independent molecules per asymmetric unit. The seven-coordinate uranium complexes 2-OH, 2-SH, and 2-SeH are chiral with an idealized $C_{3}$ symmetry, leading to a racemic mixture of the isomers. After crystallization, conglomerates of enantiomerically pure crystals of 2-SH and $\mathbf{2 - S e H}$ were isolated, while $\mathbf{2 - O H}$ crystallizes as racemate. Complex 2-TeH crystallizes in the monoclinic space group $P 2_{1} / \mathrm{n}$, featuring a slightly bent $\mathrm{U}-\mathrm{TeH}^{-}$moiety that is no longer aligned with the complexes' threefold axis. The U-Te bond vector deviates by $6.4^{\circ}$ from the normal vector, defined by the leastsquares plane calculated through the three aryloxides. This results in the loss of the crystallographically idealized $C_{3}$ symmetry. Comparing the series of uranium(IV) hydrochalcogenido species, two structural parameters are striking, and appear to be important: The U-EH bond length increases with coordination of the increasingly larger and softer elements of Group 16 downwards $(E=0,2.079(3) \AA ̊ 5,2.844(4) \AA$; Se, 2.916(2) $\AA$; Te, 3.173(1) $\AA$ ). The uranium out-of-plane shift ( $U_{\text {oop }}$; displacement of the $U$ ion of the aryloxide plane) remains virtually unchanged for 2-SH, 2-SeH, and 2-TeH, but significantly decreases for 2-OH (Table 1). The observed U-EH distances for the heavier hydrochalcogenidos ( $\mathrm{S}, \mathrm{Se}, \mathrm{Te}$ ) are essentially the sum of the ionic radii; 48 indicative of a purely ionic bonding interaction. However, the $\mathrm{U}-\mathrm{O}$ bond distance of $\mathbf{2 - O H}$ is signifycantly shorter than the sum of the ionic $U^{\mathrm{IV}}$ and the $\mathrm{O}^{2-}$ radii, already suggesting a certain degree of covalency within this bond. This hypothesis is further supported by DFT studies, previously reported for $\mathrm{U}(\mathrm{OR})_{6}$ compounds and carried out on the here reported series (vide infra). ${ }^{49}$ Additionally, the almost linear, crystallographically determined $\mathrm{U}-\mathrm{O}-\mathrm{H}$ angle $\left(175(4)^{\circ}\right)$, measured from the located $\mathrm{H}$ position (Fourier map), also is indicative for uranium-oxygen multiple bonding character. Based on the carefully conducted structural analysis of Rothwell's aryloxide complexes [(Cp) $\left.)_{2} \mathrm{M}(\mathrm{OAr})_{3}\right]$ (with $\mathrm{M}=\mathrm{Nb}$, $\left.\mathrm{Ta} ; \mathrm{Cp}=\eta^{5}-\mathrm{C}_{5} \mathrm{H}_{5}\right)^{50}$ and Parkin's complete series of phenylchalcogenates $\left[\left(\mathrm{Cp}^{*}\right)_{2} \mathrm{Zr}(\mathrm{EPh})_{2}\right]$ (with $\mathrm{Cp}^{*}=\eta^{5}-\mathrm{C}_{5} \mathrm{Me}_{5} ; \mathrm{Ph}=\mathrm{C}_{6} \mathrm{H}_{5} ; \mathrm{E}=\mathrm{O}$, $\mathrm{S}, \mathrm{Se}$, and $\mathrm{Te})$ and the sterically less hindered $\left[(\mathrm{Cp})_{2} \mathrm{Zr}(\mathrm{OPh})_{2}\right],{ }^{51}$ the authors advocated that short $\mathrm{M}-\mathrm{OR}$ bond lengths and linear $M-O-R$ angles are not inevitably a consequence of $E \rightarrow M$ lone pair donation and $\pi$-bonding but due to electrostatic contributions and steric factors. ${ }^{51}$ Similarly, DFT calculations on the closed-shell lanthanide model complexes $\left[(C p)_{2} \operatorname{Ln}(E P h)\right]$ (with $\mathrm{Ln}=\mathrm{La}$, Lu; $\mathrm{E}=\mathrm{O}, \mathrm{S}$ ), carried out by Kaltsoyannis et al., ${ }^{52}$ suggested that the linearity of the Ln-O-Ar moiety is the result of electrostatic repulsion. While the above-mentioned studies focus on arylchalcogenates, M-E-Ar, which certainly are electronically different to the hydrochalcogenates, $\mathrm{U}-\mathrm{E}-\mathrm{H}$, studied here, this discussion is closely, and surprisingly, related to the bonding in simple $\mathrm{H}-\mathrm{E}-\mathrm{H}$, discussed by Pauling and Coulson. ${ }^{53,54}$ Despite the many similarities, especially between Parkin's and the here presented series of complexes, we note that there are differences; namely, the steric profile and $\pi$ - 
bonding ability of $U$. Therefore, we favor the proposed $\pi$-bonding as the major contributor to the structurally observed and computationally supported trends in $\mathrm{U}-\mathrm{EH}$ bond lengths and $\mathrm{U}-$ $\mathrm{E}-\mathrm{H}$ angles.

Complexes 2-SH, 2-SeH, and 2-TeH feature uranium out-ofplane shifts that are in accordance with those reported for other $\mathrm{U}^{\mathrm{IV}}$ compounds of the $\left[\left({ }^{\mathrm{R}, \mathrm{R}^{\prime}} \mathrm{ArO}\right)_{3}\right.$ tacn $\left.) \mathrm{U}-\mathrm{L}_{\mathrm{ax}}\right]$ system. ${ }^{55}$ However, for $\mathbf{2 - O H}$, the observed stronger uranium-oxygen interaction leads to a weaker $\mathrm{U}-\mathrm{N}_{\text {tacn }}$ orbital overlap trans to the $\mathrm{OH}^{-}$ ligand ${ }^{25}$ and $U_{\text {oop }}$ significantly decreases $(-0.156 \AA)$. Consequently, the $\mathrm{U}-\mathrm{N}_{\text {tacn }}$ distance of 2-OH increases and the uranium ion moves closer to the aryloxide plane. The bonding parameters of the supporting ligand are very similar through the entire series and are in the range of mononuclear uranium(IV) compounds supported by a trisaryloxide-tacn-based ligand. $55-58$ The average $\mathrm{U}-\mathrm{O}_{\mathrm{Ar}}$ distances vary from 2.15 to $2.20 \AA$, and the average $\mathrm{U}-\mathrm{N}_{\text {tacn }}$ bond length are observed from 2.63 to $2.72 \AA$. All U-EH bond length of complexes 2 are in good agreement with other reported UIV-EH distances and are in the region of U-E single bonds. ${ }^{18,} 22,38,43-44,47$

In order to access the complete series of terminal uranium(IV) chalcogenido compounds, complexes $\mathbf{2}$ were treated with potassium bis(trimethylsilyl)amide (Scheme 1). The reaction was carried out in the presence of 2.2.2-cryptand $(=4,7,13,16,21,24$-hexaoxa-1,10-diazabicyclo[8.8.8]-hexacosane; 2.2.2-crypt) to encapsulate the potassium counter ion. The sterically demanding cryptand leads to a genuine chalcogenido ligand, with the $[K(2.2 .2 \text {-crypt })]^{+}$unit situated in the outer coordination sphere of the complex anion. All terminal uranium(IV) chalcogenido complexes are isostructural and crystallize in the chiral hexagonal space group $P 6_{3}$ (Figure 1, bottom). Both units, the uranium complex and the $[K(2.2 .2-$ crypt) $]^{+}$, are located on threefold crystallographic axes. Similar to the series of U-EH complexes, the chalcogenides' molecular structure is best described as a capped trigonal bipyramid. Due to the 3-fold crystallographic axis, the terminal $E^{2-}$ ligand is occupying an axial position that is exactly trans to the center of the tacn fragment (Fig. 1, bottom, and Fig. 2). Upon deprotonation, the U-E bond lengths significantly decrease (Table 1 ) and are all clearly shorter than the sum of the ions' ionic radii, which implies multiple bond character for all terminal chalcogenido complexes. To evaluate the use of covalent radii for the here presented complexes $\left[\left((\mathrm{Ad}, \mathrm{Me} A \mathrm{ArO})_{3} \mathrm{tacn}\right) \mathrm{U}(\mathrm{E}(\mathrm{H}))\right]^{0 / 1-}$, we calculated Pyykkö's additive covalent radii sums for single-, double-, and triple-bonded molecules for all of the here presented U-EH and $\mathrm{U} \equiv \mathrm{E}$ moieties. There is moderate agreement of the predicted $R_{U-\mathrm{E}}=r_{U}+r_{\mathrm{E}(\mathrm{H})}$ with the experimentally determined bond distances for $\mathbf{2}-\mathbf{O H}$ and $\mathbf{3} \equiv \mathbf{O}$. For instance, $r_{1}, r_{2}$, and $r_{3}$ values for $U_{-}, U_{=}$, and $U \equiv$ are 170, 134, and $118 \mathrm{pm}$, and for $(\mathrm{H}) \mathrm{O}-$, $(\mathrm{H}) \mathrm{O}=$, and $(\mathrm{H}) \mathrm{O} \equiv 63,57$, and $53 \mathrm{pm}$. The sum of the covalent radii are $\sum r_{\mathrm{i}} 233\left(r_{1}\right)$, to $191\left(r_{2}\right)$, and $171 \mathrm{pm}\left(r_{3}\right)$, while the experimental bond length is $207.9 \mathrm{pm}(\mathbf{2}-\mathbf{O H})$ and $186.8 \mathrm{pm}$ $(3 \equiv 0)$. An example provided by Pyykkö presents a much better fit. For instance, Liddle's hexavalent, neutral [(Tren $\left.{ }^{T I P S}\right) \mathrm{U}(\mathrm{N})$ ] (with Tren $\left.{ }^{\text {TIPS }}=\mathrm{N}\left(\mathrm{CH}_{2} \mathrm{CH}_{2} \mathrm{NSi}^{i} \mathrm{Pr}_{3}\right)_{3}\right)^{59}$ possess an experimentally determined triple bond distance of $179.9(7) \mathrm{pm}$, which compares well with the $\sum r_{3}$ value of $172 \mathrm{pm} .{ }^{60}$ This result could be understood on the basis of the electronegativity, covalence and bond polarizations, which makes the nitrido ligand a better model for the Pyykkö's covalent radii approach. However, the model brakes down badly when studying the heavier chalcogenides in $\mathrm{U}-\mathrm{EH}$ and $\mathrm{U} \equiv \mathrm{E}$ in $\mathbf{2}$ and $\mathbf{3}$. It is worth mentioning that Pyykkö's test on the present triple bond radii for the simple [O$\mathrm{U}-\mathrm{E}]^{2+}$ moiety also fails for the heavier chalcogenides. "For the $[\mathrm{O}-\mathrm{U}-\mathrm{E}]^{2+}$ moiety the $\mathrm{E}=\mathrm{O}$ result agrees with the $r_{3}$ radii, but the experimental $\mathrm{E}=\mathrm{S}$, Se distances are much longer than those predicted by the triple bond radii; see Table $6 . " 60$

The experimentally observed U-E bond lengths are slightly longer but in good agreement to other reported terminal uranium chalcogenido complexes, ranging between 1.706(9) $1.863(4) \AA(U \equiv 0), 57,61-642.382(11)-2.5220(14) \AA(U \equiv S),{ }^{21,23-}$ $24,35-37,652.533(1)-2.6463(7) \AA \AA(U \equiv S e), 21,35,39$ and $2.866(2)-$ $2.879(2) \AA \quad(\mathrm{U} \equiv \mathrm{Te}), 35,39$ respectively. Conspicuously, in the series of complexes 3 , the uranium(IV) ion is situated only slightly underneath the aryloxide plane and the $U_{\text {oop }}$ decreases to $-0.083 \AA(3 \equiv \mathbf{0}),-0.086 \AA(3 \equiv \mathbf{S}),-0.116 \AA(3 \equiv \mathbf{S e})$, and $0.180 \AA$ ( $3 \equiv \mathrm{Te})$, respectively. Apparently, due to the uranium orbital contribution to the $\mathrm{U} \equiv \mathrm{E}$ multiple bond, the $\mathrm{U}-\mathrm{N}_{\text {tacn }}$ interaction weakens and the $\mathrm{U}-\mathrm{N}_{\text {tacn }}$ distances increase compared to the hydrochalcogenido analogs.

Previously, the $U_{\text {oop }}$ metric parameter was found to be indicative for the oxidation state of the central $U^{n+}$ ion in uranium tacn complexes with a variety of axial ligands. ${ }^{55,66,67}$ The here reported series of terminal uranium(IV) chalcogenido complexes also exhibits a significant decrease of $U_{\text {oop }}$ together with an increase of the $\mathrm{U}-\mathrm{N}_{\text {tacn }}$ bond distances, which likely is due to multiple bonding interactions between the uranium ion and the axial E ligand (vide infra).

\section{Infrared vibrational spectroscopy}

Vibrational spectroscopy is very useful to determine the presence of a hydrochalcogenido ligand, $\mathrm{EH}$, since the characteristic, IR-active $\widetilde{v}_{\mathrm{EH}}$ bands are usually observed between 3700 and $1800 \mathrm{~cm}^{-1}, 4,68$ a region typically without further absorptions (with the exception of $\tilde{v}_{\mathrm{CH}}$ bands around $3000 \mathrm{~cm}^{-1}$ ). Infrared (IR) vibrational spectra of a $\mathrm{KBr}$ disc were obtained for the solid samples of all compounds at room temperature in the region from 4000 to $400 \mathrm{~cm}^{-1}$. The $\tilde{v}_{E H}$ bands were observed as sharp but weak bands at $3695 \mathrm{~cm}^{-1}(\mathbf{2}-\mathrm{OH}), 2291 \mathrm{~cm}^{-1}$ (2-SeH), and $2206 \mathrm{~cm}^{-1}$ (2-TeH), respectively, which are all in the expected range of $\mathrm{E}-\mathrm{H}$ vibration frequencies (see ESI). For the unambiguous assignment of the hydroxo band, the deuterated complex 2-OD was synthesized by stirring a solution of $\mathbf{1}$ in THF and react it with $\mathrm{D}_{2} \mathrm{O}$. The $\tilde{v}_{\mathrm{OH}}$ band disappears and a new band is detectable at $2725 \mathrm{~cm}^{-1}$, which is in reasonable agreement with the calculated value of $2688 \mathrm{~cm}^{-1}$. 69 In the IR spectrum of the non-deuterated complex, $\mathbf{2 - O H}$, a shoulder is apparent at $2725 \mathrm{~cm}^{-1}$; probably due to impurities of naturally occurring $\mathrm{D}_{2} \mathrm{O}$ in $\mathrm{H}_{2} \mathrm{O}$.

Worth mentioning, the $\tilde{v}_{S H}$ band of $\mathbf{2}-\mathbf{S H}$ could not be identified in its vibrational IR spectrum, but the hydrosulfide 
hydrogen atom was unambiguously identified by X-ray diffraction analysis and ${ }^{1} \mathrm{H}$ NMR spectroscopy (vide infra).

Overall, the isostructural terminal chalcogenido complexes 3 display identical IR vibrational absorption spectra. However, $\mathbf{3} \equiv \mathbf{0}$ features an additional absorption band at $739 \mathrm{~cm}^{-1}$, which can be assigned to the $\tilde{v}_{\cup} \equiv_{0}$ stretch (see ESI) with an absorption energy in the range of other literature reported $\mathrm{U} \equiv \mathrm{O}$ stretching frequencies $\left(741-765 \mathrm{~cm}^{-1}\right) .{ }^{58,70-71}$ Other $\tilde{v}_{U} \equiv_{E}$ stretches occur at energies lower than $400 \mathrm{~cm}^{-1}$; and therefore, are outside of the spectral detection window. ${ }^{35}$

\section{${ }^{1}$ H NMR spectroscopy}

The ${ }^{1} \mathrm{H}$ NMR spectroscopy reflects the $C_{3}$ symmetry of all complexes in solution. Due to poor solubility, the ${ }^{1} \mathrm{H}$ NMR spectra of $\mathbf{2}$ and $\mathbf{3}$ were recorded at room temperature in pyridine- $d_{5}$. In the spectra of 2-SH, 2-SeH, and 2-TeH the 79 protons of each complex give rise to 15 paramagnetically shifted and broadened signals, with a chemical shift range from 22.5 to $-103.2 \mathrm{ppm}$. The complexes exhibit diastereotopic protons at the benzyl and methylene bridges of the tacn system. The peaks of the $\mathrm{E}-\mathrm{H}$ protons were assigned in all cases to the most up-field shifted signal. The ${ }^{1} \mathrm{H}$ NMR spectrum of 2-OH is rather complicated compared to the other compounds of the series. The spectrum features only 7 signals, some of them very broadened (peak width $\approx 2.5 \mathrm{ppm}$ ), ranging from 3.7 to -25.5 $\mathrm{ppm}$. Although the proton of the terminally bound hydroxide ligand was unambiguously detected by $\mathrm{X}$-ray diffraction analysis and IR spectroscopy (vide supra), it was not observed in the ${ }^{1} \mathrm{H}$ NMR spectrum. This is likely due to accidentally isochronous proton resonances.

The spectra of the terminal uranium(IV) chalcogenido complexes 3 exhibit 14 signals assigned to the complex protons, plus three cryptate signals in the range from 107.3 to $-116.4 \mathrm{ppm}$. The proton NMR spectra of $\mathbf{3} \equiv \mathbf{E}$ support the $\mathrm{X}$-ray crystallographic results, showing all complexes to possess $C_{3}$ symmetry. Going down the group from sulfide to telluride, the range of paramagnetic shifted proton resonances slightly decreases (106.5 to -116.4 ppm (3ES); 104.4 to -115.8 ppm (3ESe); 96.9 to $-113.1 \mathrm{ppm}(3 \equiv \mathrm{Te})$ ). The cryptate protons give rise to one sharp singlet and two triplets $\left({ }^{3} \mathrm{~J}=4.6 \mathrm{~Hz}\right)$ in the diamagnetic region. These sharp and well-resolved cryptate signals are indicative of separate ion pairs in the solutions of all complexes $\mathbf{3} \equiv \mathbf{S}, \mathbf{3} \equiv \mathbf{S e}$, and $\mathbf{3} \equiv \mathbf{T e}$. Since $\mathbf{3} \equiv \mathbf{0}$ generally exhibits comparatively broad peaks in pyridine- $d_{5}$, the terminal oxo compound was additionally studied in benzene- $d_{6}$. All complex signals are now spanning a very broad range from +107.3 to $-111.9 \mathrm{ppm}$, similar to that of $\mathbf{3} \equiv \mathbf{S}, \mathbf{3} \equiv \mathbf{S e}$, and $\mathbf{3} \equiv \mathrm{Te}$. Noticeably, the cryptate signals of $\mathbf{3} \equiv \mathbf{0}$ are found to be individual singlets at 18.9 , 17.9 , and $17.0 \mathrm{ppm}$, and are paramagnetically shifted and broadened. This shift is possibly caused by a greater interaction of the [K(2.2.2-crypt) ] ${ }^{+}$counter ion with the paramagnetic uranium center in benzene- $d_{6}$ solution due to a weaker ion pair separation. In contrast to the UIV complexes with terminal hydrochalcogenides $(\mathrm{EH}=\mathrm{SH}, \mathrm{SeH}, \mathrm{TeH})$ stabilized by the $\mathrm{N}$-anchored ligand system $\left.\left(\mathrm{Ad}^{\mathrm{Me}} \mathrm{ArO}\right)_{3} \mathrm{~N}\right)^{3-}, 22$ we were not able to detect any signal in the ${ }^{77} \mathrm{Se}$ and ${ }^{125} \mathrm{Te}$ NMR spectra of complexes 2-EH and
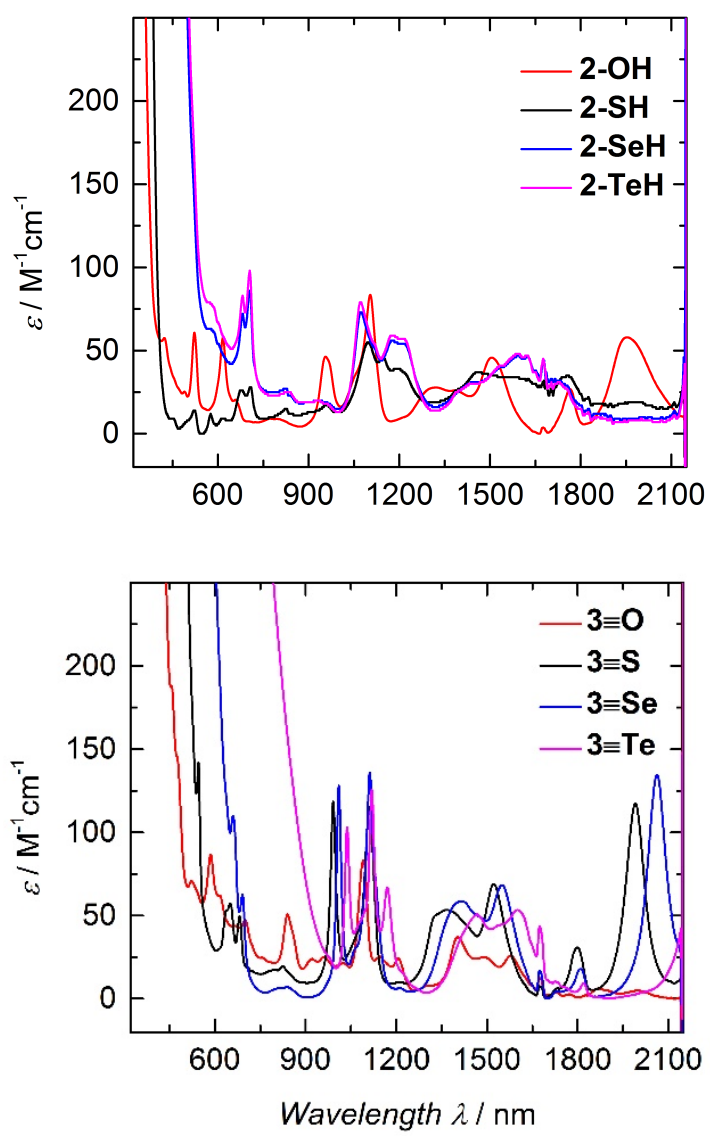

$\mathbf{3} \equiv \mathbf{E}(\mathrm{E}=\mathrm{Se}, \mathrm{Te})$; despite attempting many different combinations of different acquisition parameters (number of scans, relaxation delay, pulse angles, etc.). This is most probably due to very low solubility and higher molecular weights of these complexes compared to the previously investigated compounds, leading to very low concentrations in the deuterated solvents.

\section{Electronic Absorption Spectroscopy}

Effects of the axial $\mathrm{EH}^{-}$and $\mathrm{E}^{2-}(\mathrm{E}=\mathrm{O}, \mathrm{S}, \mathrm{Se}, \mathrm{Te})$ ligand on the electronic structure of complexes $\mathbf{2}$ and $\mathbf{3}$ were studied by UV/vis/NIR absorption spectroscopy (Fig. 3). The retention of symmetry and core structure throughout the series of complexes $\mathbf{2}$ and $\mathbf{3}$ (in solution) offers a unique opportunity for electronic structure investigations, since all differences can be traced back to the uranium-hydrochalcogenido and chalcogenido axial ligands.

Characteristic for the UV/vis spectra of complexes 2-SeH and 2-TeH is the broad absorption below $600 \mathrm{~nm}$ (Fig. 3, top), featuring a shoulder at $438 \mathrm{~nm}$ that is resolved in spectra of further diluted samples (see SI). Due to the relatively high $\varepsilon$ values of the shoulder $\left(\varepsilon=890 \mathrm{M}^{-1} \mathrm{~cm}^{-1}(2-\mathrm{SeH}), 1650 \mathrm{M}^{-1} \mathrm{~cm}^{-1}\right.$ (2-TeH)), these absorption bands can either be assigned to Laporte-allowed $5 f-6 d$ or ligand-to-metal charge transfer transitions. The soft, purely $\sigma$-donating $\mathrm{SeH}^{-}$and $\mathrm{TeH}^{-}$ligands only create a small crystal-field splitting, with the $6 d$ orbitals lying roughly above the $5 f$ orbitals, whereas the harder $\mathrm{OH}^{-}$and $\mathrm{SH}^{-}$ 
ligands are creating a significant larger energy gap between the $5 f$ and $6 d$ orbitals, shifting these absorption bands further into the UV region.

Fig. 3: Vis/NIR electronic absorption spectra of hydrochalcogenido complexes $\mathbf{2}$ (top, $5 \mathrm{~mm}$ in pyridine), and chalcogenido complexes 3 (bottom, $5 \mathrm{~mm}$ in pyridine), measured at $25^{\circ} \mathrm{C}$. A figure with vertical separations is found in the SI.

The vis/NIR region of complexes $\mathbf{2}$ shows narrow absorption bands with weak to moderate extinction coefficients $\varepsilon=$ $5-100 \mathrm{M}^{-1} \mathrm{~cm}^{-1}$ (Fig. 3, top), characteristic of tetravalent uranium ions. $^{22}$ The spectra of $\mathbf{2 - S e H}$ and 2-TeH feature 12 absorptions between 600 to $2200 \mathrm{~nm}$ and the absorption signals of both complexes are nearly superimposable over the entire vis/NIR range. Accordingly, spin-orbit coupling and crystal-field splitting is nearly identical in these two complexes. Ascending the chalcogenide group, the harder $\mathrm{SH}^{-}$ligand of 2SH is responsible for a significant decrease of the electronic absorption intensity with the molar extinction coefficient nearly halve compared to 2-SeH and 2-TeH. The absorption energies remain virtually unchanged.

Finally, the vis/NIR spectrum of 2-OH strongly differs from those of the remaining complexes of the hydrochalcogenido series. Complex $\mathbf{2}-\mathbf{O H}$ exhibits 10 absorption bands in the region between 400 to $2200 \mathrm{~nm}$, with a distinctly different absorption pattern compared to 2-SH, 2-SeH, and 2-TeH. Since $\mathrm{OH}^{-}$is the hardest ligand in the chalcogenido series, it apparently creates the strongest crystal-field splitting and the covalent contributions of the $5 f$ orbitals to the $\mathrm{U}-\mathrm{O}$ bond might lead to this dramatic change of electronic transitions.

Upon deprotonation, changes in the NIR region of complexes $\mathbf{3}$ are observed (Fig. 3, bottom). The intensities of the absorption bands slightly increase $\left(\varepsilon=10-136 \mathrm{M}^{-1} \mathrm{~cm}^{-1}\right)$ in comparison to the hydrochalcogenido complexes 2 . The charge-transfer absorptions are shifted to higher wavelengths and a bathochromic shift is observed, increasing from $O$ to Te $\left(\lambda_{C T}=509 \mathrm{~nm}\right.$ (3E0), $\lambda_{C T}=607 \mathrm{~nm}(3 \equiv S), \lambda_{C T}=761 \mathrm{~nm}(3 \equiv S e), \lambda_{C T}=997 \mathrm{~nm}$ $(\mathbf{3} \equiv \mathrm{Te})$ ). As a result, the $\mathbf{3} \equiv$ Se and $\mathbf{3} \equiv$ Te feature less absorption bands in the NIR region, since the high-energy $f-f$ transitions get superimposed by intense charge transfer absorptions. Complexes $\mathbf{3} \equiv \mathbf{S}, \mathbf{3} \equiv \mathbf{S e}$, and $\mathbf{3} \equiv \mathbf{T e}$ show similar absorption

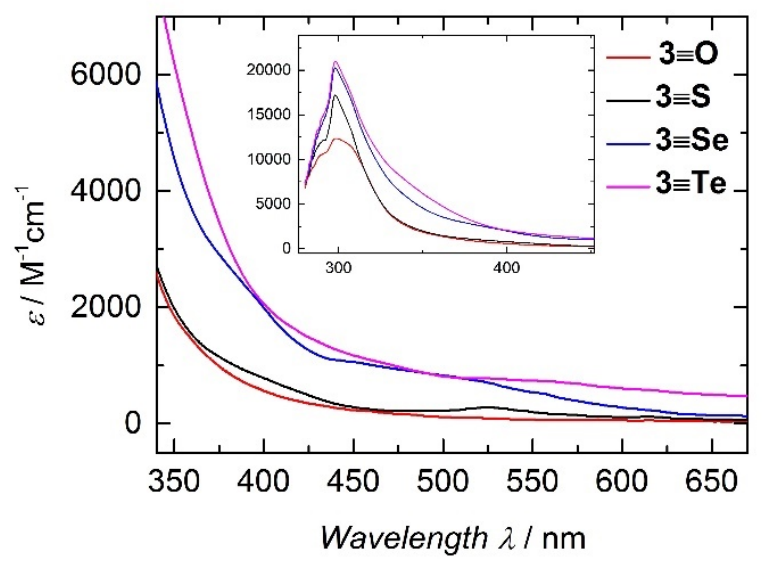

patterns, but for the softer chalcogenido ligands, Se and Te, the $f-f$ transition energies are shifted to higher wavelengths. The $\mathbf{3} \equiv$ Te absorption band starting at around $2100 \mathrm{~nm}$ is superimposed by strong vibrational overtone absorptions of the solvent and, therefore, is not shown. As expected, the electronic absorption spectrum for the terminal oxo species is distinctively different from its heavier analogs. As seen for the hydrochalcogenido complexes, the electronic transitions of $\mathbf{3} \equiv \mathbf{0}$ are not in line with the other absorptions observed for the series of the heavier chalcogenido complexes. The terminal oxo complex features 16 absorption bands in the region between 525 $2000 \mathrm{~nm}$, with molar extinction coefficients consistently lower than the rest of the series $\left(\varepsilon=5-87 \mathrm{M}^{-1} \mathrm{~cm}^{-1}\right)$. However, the NIR region of $\mathbf{3} \equiv \mathbf{0}(1250-1700 \mathrm{~nm})$ does not differ signifycantly compared to the rest of chalcogenido complexes and exhibits comparable intensities and line broadening.

Fig. 4: UV/vis electronic absorption spectra of chalcogenido complexes 3 (0.01 mM in pyridine), measured at $25^{\circ} \mathrm{C}$.

While complexes $\mathbf{3} \equiv \mathbf{S}, \mathbf{3} \equiv \mathbf{S e}$, and $\mathbf{3} \equiv \mathbf{T e}$ exhibit moderately intense absorption in the visible region of the spectrum, $\mathbf{3} \equiv \mathbf{0}$ shows no additional absorption in the UV/vis region (Fig. 4). For $\mathbf{3} \equiv \mathbf{S}$, a charge transfer band is located at $\lambda=524 \mathrm{~nm}\left(\varepsilon=300 \mathrm{M}^{-}\right.$ $\left.{ }^{1} \mathrm{~cm}^{-1}\right)$, complexes $\mathbf{3} \equiv$ Se and $\mathbf{3} \equiv$ Te feature very broad bands starting at around $625 \mathrm{~nm}(3 \equiv \mathrm{Se})$ and $800 \mathrm{~nm}(3 \equiv \mathrm{Te})$.

\section{Magnetism}

Theoretical considerations of the magnetic moments of uranium complexes are not straightforward because spin-orbit coupling contributions are non-negligible. As a result, the room temperature (RT) magnetic moments are often lower than calculated. However, the $\mu_{\text {eff }}$ values at very low temperatures (usually $2 \mathrm{~K}$ ), the RT values, and the temperature-dependency of the magnetization data can be quite informative with respect to oxidation state and crystal-field effects. ${ }^{45,56}$ At $2 \mathrm{~K}$, uranium(IV) $f^{2}$ complexes often possess a small residual magnetic moment due to a non-magnetic ${ }^{3} \mathrm{H}_{4}$ ground state. ${ }^{72}$ This residual magnetic moment at low temperature (generally $0.3-$ $\left.0.8 \mu_{B}\right)$ is due to mixing of the magnetic ground state with excited magnetic states in an applied magnetic field and is defined as temperature-independent paramagnetism (TIP). ${ }^{45}$ In the presence of strong-field ligands, however, a non-negligible crystal (ligand) field may interfere with spin-orbit coupling and significantly effect the complexes magnetic behavior; especially at low temperatures.

The temperature-dependent magnetic moments of the hydrochalcogenido complexes $\mathbf{2}$, determined by SQUID magnetometry, are shown in Fig. 5 (top). Clearly, the electronic structure of the uranium(IV) complexes 2-SeH and 2-TeH is very similar as seen in the overlay of the magnetic moments (see UV/vis/NIR spectroscopy). The data traces exhibit nearly identical values over the entire temperature range $\left(2 \mathrm{~K}: 0.54 \mu_{B}\right.$ (2SeH), $0.51 \mu_{B}$ (2-TeH); $300 \mathrm{~K}: 2.89 \mu_{B}$ (2-SeH), $2.96 \mu_{B}$ (2-TeH)). Overall, compounds 2-SeH and 2-TeH show the typical $\mu_{\text {eff }}$ temperature-dependency of uranium(IV) complexes, exhibiting 
a monotonous increase with increasing temperature. ${ }^{43,55-}$ $56,66,72$ This is due to the relative small crystal-field splitting of these compounds that allows the energetically higher laying magnetic states to get thermally populated with higher temperatures. In contrast, $\mathbf{2}-\mathbf{O H}$ and $\mathbf{2}-\mathbf{S H}$ show a different temperature-dependency of the magnetic moments: 2-SH exhibits an elevated magnetic moment of $0.96 \mu_{B}$ at $2 \mathrm{~K}$, which increases to $2.85 \mu_{B}$ at room temperature. Differences that are even more distinct are present in the case of 2-OH. At $2 \mathrm{~K}$, this uranium(IV) hydroxo complex exhibits a significantly higher magnetic moment of $1.12 \mu_{B}$, rising with a steep slope, and increasing up to $2.48 \mu_{B}$ at $50 \mathrm{~K}$. At temperatures above $100 \mathrm{~K}$, the magnetic moments of $2-0 \mathrm{OH}\left(2.81 \mu_{B}\right.$ at $\left.300 \mathrm{~K}\right)$ are very similar to those of the rest of the $\mathrm{U}-\mathrm{EH}$ series.
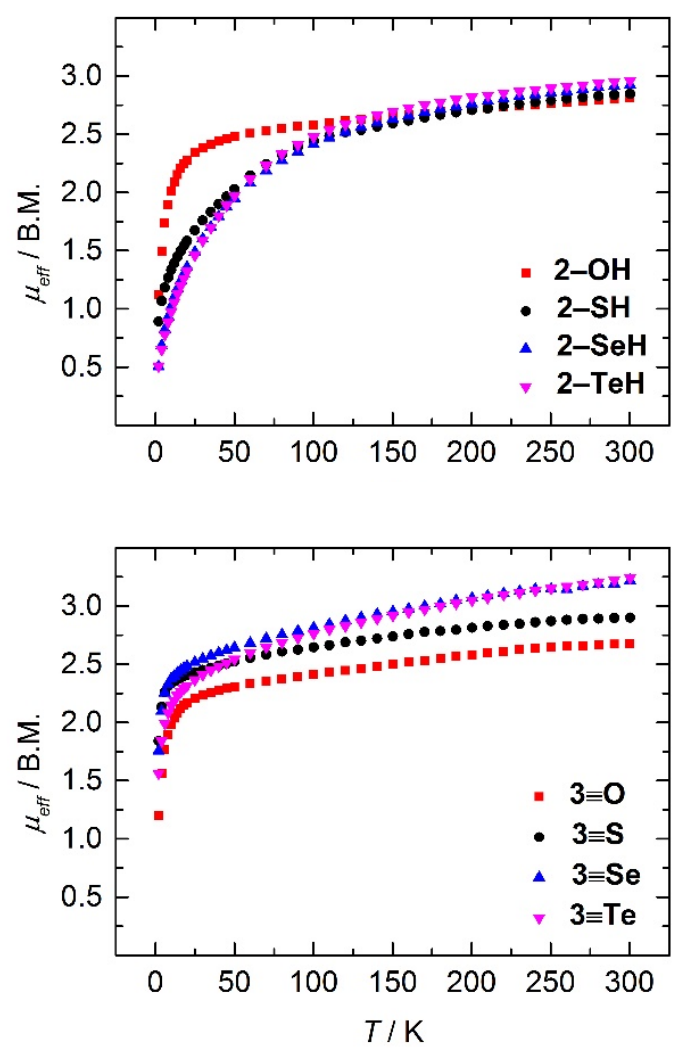

Fig. 5: Temperature-dependent SQUID magnetization data of complexes $\mathbf{2}$ (top) and $\mathbf{3}$ (bottom). The depicted data trace $\mu_{\text {eff }}$ $v s$. $T$ of each compound is an average of independently synthesized and measured samples (see ESI).

Pyykkö et al. have attributed the characteristically short U$\mathrm{F}$ bond to strong electrostatic attraction and strong covalent bonding. The substantial multiple bond character in $\mathrm{U}-\mathrm{F}$ bonds results from the fact that the $\mathrm{F}$ ligand acts as a $\sigma$ acceptor and $\pi$ donor. 49,73 Due to hydroxide being isoelectronic to fluoride, and both being considered "hard" ligands, the similar crystal field splitting and resulting magnetism is not surprising. It is, however, remarkable that the magnetic moments' temperature dependence and absolute values of the considerably softer, but still isoelectronic, arsenide ligand in Liddle's [(Tren $\left.{ }^{\text {TIPS }}\right) \mathrm{U}\left(\mathrm{AsH}_{2}\right)$ ] (with Tren $\left.{ }^{\text {TIPS }}=\mathrm{N}\left(\mathrm{CH}_{2} \mathrm{CH}_{2} \mathrm{NSi}^{i} \mathrm{Pr}_{3}\right)_{3}\right)$ are remarkably similar to 2$\mathrm{OH}$, while the magnetism of [(Tren $\left.\left.{ }^{\mathrm{TIPS}}\right) \cup\{\operatorname{AsH}(\mathrm{K})\}\right]$ and $\left[\left\{\left(\text { Tren }^{\mathrm{TIPS}}\right) \mathrm{U}\left(\mathrm{AsK}_{2}\right)\right\}_{4}\right]^{34}$ is more reminiscent of the heavier analogues of 2-EH (with $\mathrm{E}=\mathrm{S}, \mathrm{Se}, \mathrm{Te})$ and $\left[\left((\mathrm{Ad}, \mathrm{Me} A \mathrm{ArO})_{3} \mathrm{mes}\right) \mathrm{U}(\mathrm{X})\right.$ (THF)] (with $\mathrm{X}=\mathrm{Cl}, \mathrm{Br}, \mathrm{I}) .^{74}$ This illustrates how point charge and covalence impact the magnetic behavior.

In summary, all temperature-dependent magnetization measurements of complexes $\mathbf{2}$ validate a +IV oxidation state of the uranium ions, and qualitatively demonstrate the non-negligible effects of the single, axial hydrochalcogenide ligand on the crystal-field splitting.

The entire series of terminal uranium(IV) chalcogenido complexes 3 were also studied by SQUID magnetization measurements. Compared to the analogous series of $\left[\left(\mathrm{R}_{2} \mathrm{~N}\right)_{3} \mathrm{U}(\mathrm{E})\right]$ (with $\left.\mathrm{E}=\mathrm{O}, \mathrm{S}, \mathrm{Se}, \mathrm{Te} ; \mathrm{R}=\mathrm{SiMe}_{3}\right)$, for which Hayton et al. reported magnetic data for $\mathrm{E}=\mathrm{O}$, Se, and Te $(4-300 \mathrm{~K}), 35$ complexes 3 feature a rather unusual variable-temperature magnetization behavior with remarkably high $2 \mathrm{~K}$ magnetic moments $\left(\mu_{\text {eff }}=1.18 \mu_{B}(\mathbf{3} \equiv \mathbf{0}), \mu_{\text {eff }}=1.85 \mu_{B}(\mathbf{3} \equiv \mathbf{S}), \mu_{\text {eff }}=1.79 \mu_{B}(\mathbf{3} \equiv \mathbf{S e})\right.$, $\left.\mu_{\text {eff }}=1.56 \mu_{B} \quad(3 \equiv \mathrm{Te})\right)$ and a very strong temperaturedependency in the low temperature range $(2-20 \mathrm{~K})$. As already seen for $\mathbf{2}-\mathbf{O H}$, the terminal chalcogenido ligands of $\mathbf{3} \equiv \mathbf{E}$ apparently create a strong crystal-field with low-lying magnetic states close in energy. At temperatures above $20 \mathrm{~K}$, only a moderate increase of $\mu_{\text {eff }}$ is noticed and, at room temperature, each species reaches rather variable values of $2.67 \mu_{B}(\mathbf{3} \equiv \mathbf{0})$, $2.86 \mu_{B}(\mathbf{3} \equiv \mathbf{S}), 3.19 \mu_{B}(\mathbf{3} \equiv \mathbf{S e})$, and $3.22 \mu_{B}(\mathbf{3} \equiv \mathrm{Te})$, respectively. It is noteworthy that the difference in $\mu_{\text {eff }}$ of compounds $\mathbf{3}$ at room temperature is not due to different covalency (see Theoretical Studies).

\section{Theoretical Studies}

Geometry optimizations at the DFT level without symmetry constraints were performed for both the hydrochalcogenido 2EH and chalcogenido series $\mathbf{3} \equiv \mathbf{E}$. The non-interacting $\mathrm{K}^{+}$ counter ions of complexes $\mathbf{3}$ were not included in the calculations. Molecular orbital (MO) and natural bond orbital (NBO) analyses of the $\mathrm{U}-\mathrm{E}$ bonds were performed on the optimized structures of complexes $\mathbf{2}$ and $\mathbf{3}$.

The NBO analyses of the series of hydrochalcogenido compounds $\mathbf{2}$ clearly reveals $\sigma$-bond interaction between the uranium(IV) center and the hydrochalcogenido ligand (Fig. 6 and Table 2). Additionally, at the second order-acceptor level, some $\pi$-type interactions between the lone pairs of the respective hydrochalcogenido ligands and a $6 d / 5 f$ hybrid orbital of the uranium ion is observed. In the case of $\mathbf{2 - O H}$, however, $\pi$-donation is more pronounced, which is due to significant electron density donation of both oxygen $p$ lone pairs into the uranium- 
based orbitals $\left(122 \mathrm{kcal} \mathrm{mol}^{-1}\right.$ at the second order donoracceptor NBO). This value is characteristic of donation when a $\pi$ bond exists that was not found by first order NBO analysis. Consequently, 2-OH is best described with a formal $U \equiv O$ triple bond. This interpretation is in agreement with the complexes' crystallographically determined short $\mathrm{U}-\mathrm{OH}$ bond and linear $\mathrm{U}-$ $\mathrm{O}-\mathrm{H}$ unit as well as spectroscopic and magnetic features; all characteristic of multiple bond character within the $\mathrm{U}-\mathrm{O}$ bond.

In contrast, for the heavier complexes, 2-SH, 2-SeH, and 2$\mathrm{TeH}$, significantly weaker $\pi$-donations are found, involving only one of the two chalcogen atom lone pairs $(43,45$, and $37 \mathrm{kcal}$ $\mathrm{mol}^{-1}$ for 2-SH, 2-SeH, and 2-TeH, respectively). Accordingly, the bonding situation in 2-SH, 2-SeH, and 2-TeH, is best described with a U-EH single bond interaction. Contrary to these results, Andrez et al. recently reported a terminal uranium(IV) hydrosulfido species, namely $\left[\left(\left({ }^{t} \mathrm{BuO}\right)_{3} \mathrm{SiO}\right)_{4} \mathrm{U}(\mathrm{SH})\right]^{-}$, featuring double bond character within the $\mathrm{U}=\mathrm{SH}$ bond. ${ }^{23}$ Our previous studies indicated that, in case of $\mathbf{2 - S H}$, the pyramidalized uranium ion has an efficient overlap with the $\mathrm{N}$ donor atoms of the chelate's tacn moiety. This results in a trans influence, inducing a weaker $\mathrm{U}-\mathrm{SH}$ bond, formally described as a single bond. ${ }^{24}$ Now, the same bonding situation also was established for the respective hydroselenido and hydrotellurido complexes 2-SeH and 2-TeH. The magnitude of overlap between the axial ligand lone pair and uranium hybrid orbital, and the resulting strength of the interaction, also is expressed by the different $\mathrm{U}-\mathrm{E}-\mathrm{H}$ angles of the complexes (Table 2). The almost linear $\mathrm{U}-\mathrm{O}-\mathrm{H}$ angle of 2-OH exhibits a strong $\pi$-type interaction, whereas the small $\mathrm{U}-\mathrm{E}-\mathrm{H}$ angles of $\mathbf{2 - S H}, \mathbf{2 - S e H}$, and $\mathbf{2 - T e H}$ indicate negligible $\pi$-bonding; in line with the XRD results (vide supra). While there is a significant differences between the experimentally and theoretically determined $\mathrm{U}-\mathrm{E}-\mathrm{H}$ angles (with XRD calculated positions for $E=S$, Se, Te), the general trend is reproduced; including the same $\mathrm{U}-\mathrm{E}-\mathrm{H}$ angle for $\mathbf{2 - S e H}$ and $\mathbf{2 -}$ TeH.

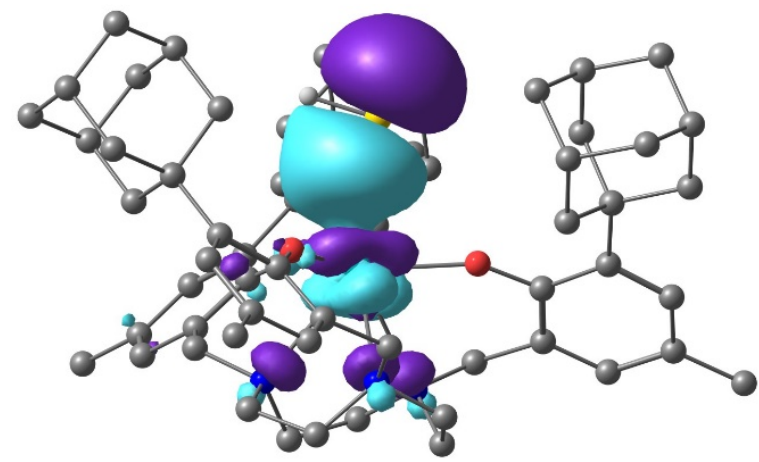

Fig. 6: 3D representation of the $\sigma$ bond for complex 2-SeH.

In complexes 2-EH, the U-E interaction is strongly polarized towards the $\mathrm{EH}^{-}$ligand, with only 15 to $24 \%$ uranium character (Table 2). Descending the chalcogenide group, the U-EH bond becomes less polarized, which is due to the reduced electronegativity of the donor atoms and better U-E orbital overlap. The bond participation of uranium is significantly higher for complex 2-OH compared to complex 2-SH (20\% for $2-\mathbf{O H}$, and only $15 \%$ for $\mathbf{2}-\mathbf{S H}$ ), demonstrating multiple bond character within the $\mathrm{U}-\mathrm{O}$ interaction.

The Wiberg bond indices (WBI) have been calculated to analyze the strength of the uranium chalcogen bonds in compounds 2 and $\mathbf{3}$. Interestingly, the WBI of the respective complexes $\mathbf{2}$ are in the same order of magnitude but increase descending the chalcogenide group (WBIs: 0.95 (2-OH), 1.06 (2$\mathrm{SH}), 1.10(2-\mathrm{SeH})$, and $1.13(\mathbf{2}-\mathrm{TeH}))$. Counterintuitively, the U$\mathrm{OH}$ interaction is the most covalent in the series 2-EH. This observation is in agreement with the a report of Andersen and coworkers, who analyzed the bonding properties of uranium oxido and imido complexes $\left[\mathrm{Cp}_{2} * \mathrm{UO}\right]$ and $\left[\mathrm{Cp}_{2} * \mathrm{UNR}\right] .^{75}$

In line with previous studies on uranium(IV) complexes with terminal sulfido ligands, $\mathbf{3} \equiv \mathbf{S},,^{23-24}$ the bonding analyses of UIV complexes $\mathbf{3} \equiv \mathbf{0}, \mathbf{3} \equiv \mathrm{Se}$, and $\mathbf{3} \equiv$ Te clearly reveal triple $\mathrm{U} \equiv \mathrm{E}$ bond character of the uranium-chalcogenido interaction (Fig. 7 and Table 2). The orbital composition of the triple bond is quite similar across the entire series. The $\sigma$-bond is described by the donation of electron density from an $s p$ hybrid orbital of the chalcogenido ligand into the empty $6 d_{z}^{2} / 5 f_{z}^{3}$ hybrid orbital of the UIV ion. Since the bond contribution of the $5 f$ orbitals is often claimed to be the reason for the unique reactivity of uranium compounds, ${ }^{38,40,45,55,76}$ the exact composition of the $6 d_{z}^{2} / 5 f_{z}^{3}$ hybrid orbital was studied in more detail. The $f$ character of the hybrid orbitals of $\mathbf{3} \equiv \mathrm{E}$ varies from about 40 to $60 \%$ across the series. Interestingly, the harder chalcogen atoms cause a more pronounced $f$ character of the $6 d_{z}{ }^{2} / 5 f_{z}{ }^{3}$ hybrid orbital compared to the softer chalcogen ligands. It is noteworthy, that in the $\sigma$-bonding of $\mathbf{3} \equiv$ Se and $\mathbf{3} \equiv \mathrm{Te}$, the U UV hybrid orbital exhibit $7 s$ orbital character $(10 \% 7 s$ character for $3 \equiv$ Se and $15 \%$ for $3 \equiv \mathrm{Te}$ ), partially replacing the $5 f$ orbital contribution. Finally, the two $\pi$-bonding orbitals are formed by interaction of both chalcogen $p$ lone pairs and the hybrid $6 d_{\pi} / 5 f_{\pi}$ orbitals of uranium. 


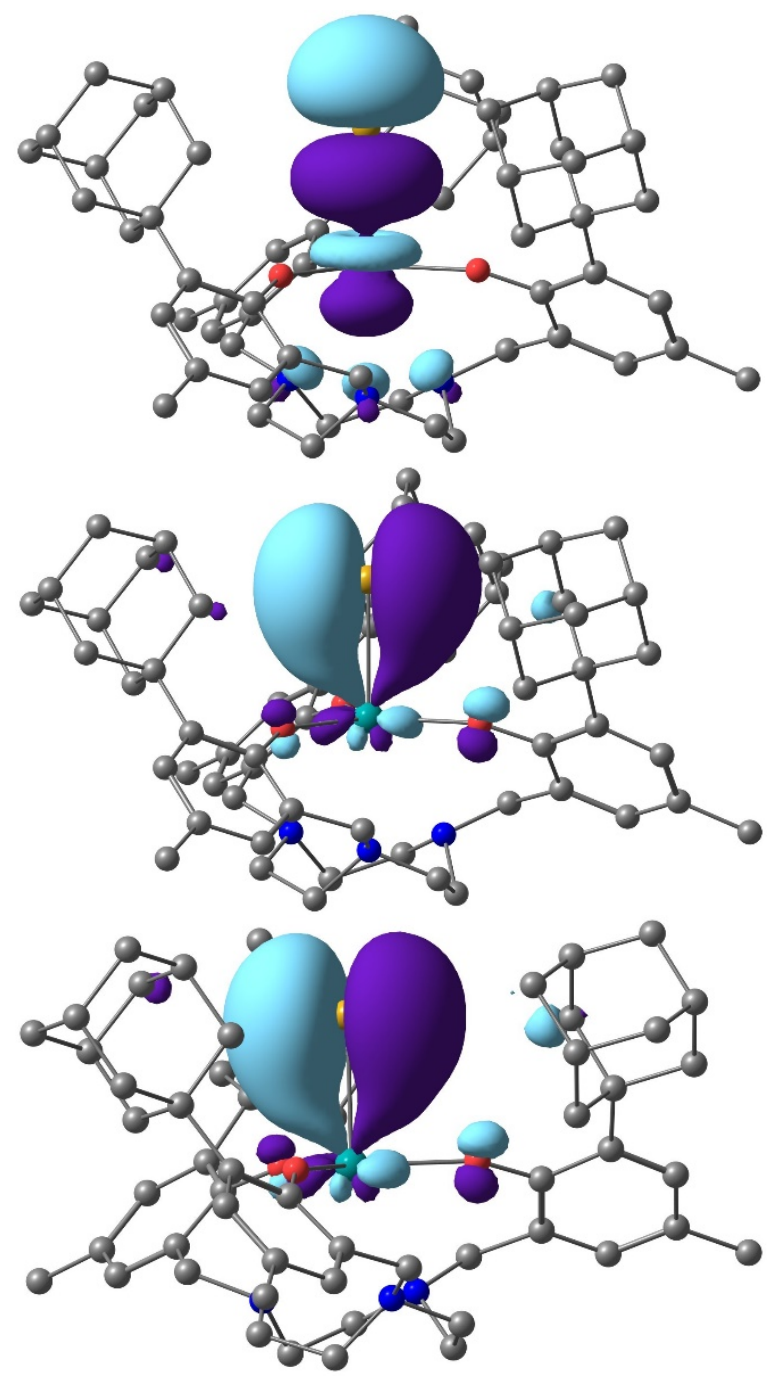

Fig. 7: 3D representation of the $\sigma$ and $\pi$ bonds for complex 3Se. Both $\pi$-bonds are rotated to be depicted in the plane of sight. The iso-surface plot level is set at 0.03 , the default value of ChemCraft and all other programs.

Despite the significant covalent character of the U-E interaction, the formal triple bond is strongly polarized towards the terminal chalcogenido ligand. As depicted in Fig. 7, the highest electron density (higher than $70 \%$ in all cases) of the MOs is located at the chalcogenido atom. However, the bond polarization decreases with decreasing electronegativity of the respecttive chalcogen atoms $(\mathrm{O}>>\mathrm{S} \geq \mathrm{Se}>\mathrm{Te})$. The natural charge at the uranium center also is a good indicator for the ionic character of the $\mathrm{U}-\mathrm{E}$ bond. The $\mathrm{U}$ natural charge significantly decreases from $1.7(\mathbf{3} \equiv \mathbf{0})$ to $1.0(3 \equiv \mathrm{Te})$ (Table 2$)$. Interestingly, complexes $\mathbf{3} \equiv \mathbf{S}$ and $\mathbf{3} \equiv \mathbf{S e}$ feature natural charges comparable to $\mathbf{3} \equiv \mathbf{T e}(1.2$ for $\mathbf{3} \equiv \mathbf{S}$, and 1.1 for $\mathbf{3} \equiv \mathbf{S e}$ ), thus, emphasizing a more covalent bonding interaction in complexes with the softer chalcogenido ligands. In conclusion, the computational studies reveal that complex $\mathbf{3} \equiv \mathbf{0}$ features the highest $f$ orbital contribution within the U-E series, however, it also illustrates the highest ionic character compared to the rest of the series. 


\section{ARTICLE}

Table 2: Computational results obtained for complexes 2-EH and $\mathbf{3} \equiv \mathbf{E}$.

\begin{tabular}{|l|l|l|l|l|l|l|l|l|}
\hline & $2-\mathrm{OH}$ & $2-\mathrm{SH}$ & $2-\mathrm{SeH}$ & $2-\mathrm{TeH}$ & $3 \equiv 0$ & $3 \equiv \mathrm{S}$ & $3 \equiv \mathrm{Se}$ & $3 \equiv \mathrm{Te}$ \\
\hline Wiberg bond index & 0.95 & 1.06 & 1.10 & 1.13 & 1.75 & 1.99 & 2.00 & 1.99 \\
\hline U natural charge & 1.4 & 1.4 & 1.4 & 1.3 & 1.7 & 1.2 & 1.1 & 1.0 \\
\hline E natural charge & -0.5 & -0.5 & -0.4 & -0.2 & -0.8 & -0.7 & -0.6 & -0.6 \\
\hline U contribution in $\sigma$ bond & $20 \%$ & $15 \%$ & $21 \%$ & $24 \%$ & $15 \%$ & $23 \%$ & $25 \%$ & $27 \%$ \\
\hline E contribution in $\sigma$ bond & $80 \%$ & $85 \%$ & $79 \%$ & $76 \%$ & $85 \%$ & $77 \%$ & $75 \%$ & $73 \%$ \\
\hline U contribution in $\pi$ bonds & - & - & - & - & $20 \%$ & $22 \%$ & $23 \%$ & $28 \%$ \\
\hline E contribution in $\pi$ bonds & - & - & - & - & $80 \%$ & $78 \%$ & $77 \%$ & $72 \%$ \\
\hline Distance U-E in $\AA$ & 2.14 & 2.83 & 2.95 & 3.19 & 1.97 & 2.58 & 2.70 & 2.94 \\
\hline$U_{\text {oop }}$ in $\AA$ & -0.180 & -0.241 & -0.232 & -0.227 & -0.041 & -0.016 & -0.018 & -0.016 \\
\hline$\Varangle$ U-E-H in ${ }^{\circ}$ & $157^{\circ}$ & $100^{\circ}$ & $94^{\circ}$ & $94^{\circ}$ & - & - & - & - \\
\hline
\end{tabular}


"This is the peer reviewed version of the following article: [Dalton Trans., 2019, 48, 10853] which has been published in final form at [Link to final article using the DOI: 10.1039/c9dt00530grsc.li/dalton]. This article may be used for non-commercial purposes in accordance with the Royal Society of Chemistry Terms and Conditions for Self-Archiving."

\section{ARTICLE}

\section{Conclusions}

In summary, together with the previously reported sulfur complexes [((Ad,MeArO $\left.\left.)_{3} \operatorname{tacn}\right) \mathrm{U}^{\mathrm{IV}}(\mathrm{SH})\right](\mathbf{2}-\mathrm{SH})$ and $\left[\left((\mathrm{Ad}, \mathrm{Me} \mathrm{ArO})_{3-}\right.\right.$ $\left.\operatorname{tacn}) \mathrm{U}^{\mathrm{IV}}(\mathrm{S})\right]^{-}(\mathbf{3} \equiv \mathbf{S})^{-}$, we here present the synthesis and characterization of a complete series of uranium(IV) complexes bearing terminal chalcogenido and hydrochalcogenido ligands, including the rare hydroxide, $\left[\left((\mathrm{Ad}, \mathrm{Me} A \mathrm{ArO})_{3} \mathrm{tacn}\right) \mathrm{U}^{\mathrm{IV}}(\mathrm{OH})\right](\mathbf{2}-\mathbf{O H})$. All complexes 2-EH and $\mathbf{3} \equiv \mathbf{E}$ are supported by the $(\mathrm{Ad}, \mathrm{Me} \mathrm{ArO})_{3^{-}}$ tacn $^{3-}$ chelate and feature seven coordinate, $C_{3}$-symmetric uranium coordination with axially bound $\mathrm{EH}^{-}$and $\mathrm{E}^{2-}$ ligands. The molecular geometry is best described as a capped trigonal bipyramid.

The formal uranium +IV oxidation state in all complexes was confirmed by UV/vis/NIR absorption spectroscopy and SQUID magnetometry. Hence, the compounds' differences in their electronic structures are entirely due and assignable to their different axial chalcogenide ligands. Single-crystal XRD and computational DFT studies reveal an ionic bonding situation for the softer hydrochalcogenido ligands $(\mathrm{SH}, \mathrm{SeH}, \mathrm{TeH})$ and a more covalent bonding interaction for $\mathbf{2 - O H}$. As a result, the electronic structure of 2-OH strongly differs from the rest of the hydrochalcogenido series, which is illustrated by a different band pattern in its absorption spectrum and a more distinct temperature-dependency of its magnetic moment observed in SQUID magnetization experiments. Deprotonation of hydrochalcogenido complexes 2-EH by $\mathrm{KN}\left(\mathrm{SiMe}_{3}\right)_{2}$, in the presence of 2.2.2cryptand, results in the formation of terminal uranium chalcogenido complexes $\mathbf{3} \equiv \mathbf{E}$. Solid-state structure analyses revealed the formation of separate ion pairs for complexes $\mathbf{3}$ with the [K(2.2.2-crypt) $]^{+}$unit situated in the complexes' outer coordination sphere. Furthermore, complexes $\mathbf{3}$ exhibit interesting lowtemperature magnetization behavior with a strong increase of the magnetic moment below $20 \mathrm{~K}$. This rather unusual temperature-dependency of the magnetic moment is a consequence of the covalent uranium chalcogenido interaction and the resulting ligand field splitting. The magnetic moment of $\mathbf{2 - O H}$ shows a similar temperature-dependency to that of complexes
3. Single crystal XRD and DFT analyses support the multiple bonding character of the $\mathrm{U}-\mathrm{OH}$ bond.

DFT computational analyses are in agreement with the experimental results, and further provide detailed insight into the uranium(IV) chalcogen bond. Whereas compound 2-OH features multiple bond character, the rest of the series only exhibits $\mathrm{U}-\mathrm{EH}$ single bonds. Regardless, comparison of the WBIs reveals a weaker $\mathrm{U}-\mathrm{EH}$ bond of 2-OH compared to the more ionic bonds of 2-SH, 2-SeH, and 2-TeH. In contrast, unambiguous triple bond character was established for terminal chalcogenido complexes $\mathbf{3} \equiv \mathbf{E}$ that feature one $\sigma$ - and two, nearly degenerate $\pi$-type interactions. The $f$ orbital character of the uranium $6 d / 5 f$ hybrid orbitals varies from 40 to $60 \%$, with the higher $f$ orbital percentage for the harder chalcogenido ligands. The U-E bond polarization of $\mathbf{3}$ decreases with the electronegativity of the axial chalcogenide ligand. These results illustrate that the UIV ion in $\mathbf{3}$ 三E forms a more covalent bond with the softer chalcogenido ligands. However, in contrast to observations in transition metal chemistry, a more covalent bond in uranium chemistry does not necessarily imply stronger overall bonding.

Notably, this study reveals three different types of the "trans influence", a thermodynamic phenomenon that is reflected in structural changes of the complexes' ground state. Two different trans influences are observed for the series of $U_{-}$ $\mathrm{EH}$ compounds, and another one for $\mathrm{U} \equiv \mathrm{E}$ complexes. Within the series of 2-EH complexes, $\mathbf{2 - O H}$ is different from the heavier analogues 2-SH, 2-SeH, and 2-TeH. In 2-OH, significant $\mathrm{O} \rightarrow \mathrm{U}$ $p \pi-d \pi$ lone pair donation leads to weakened $\mathrm{U}-\mathrm{N}_{\text {tacn }}$ interactions. Accordingly, the trans influence in $\mathrm{U}-\mathrm{OH}$ manifests in a short $\mathrm{U}-\mathrm{O}$ bond, a linear $\mathrm{U}-\mathrm{O}-\mathrm{H}$ angle, and a $\mathrm{U}$ ion that "moves" towards its $\mathrm{OH}$ ligand for enhanced orbital overlap and $\pi$-bonding; and thus, resides close to the plane of the three aryloxide oxygen atoms ( $U_{\text {oop }}-0.15 \AA$ ). In contrast, for 2-EH, with the softer chalcogenides $E=S$, Se, and Te, the $U$ ion seeks an efficient bonding with the tacn $\mathrm{N}$ ligands, as previously established for $\mathrm{U}-\mathrm{SH} ;{ }^{24}$ and consequently, pyramidalizes towards the tacn macrocycle. This leads to significantly larger $U_{\text {oop }}$ shifts (0.27 to $-0.3 \AA$ ), shorter $\mathrm{U}-\mathrm{N}_{\text {tacn }}$ and longer $\mathrm{U}-\mathrm{EH}$ bonds (with 
single bond character) with $\mathrm{U}-\mathrm{E}-\mathrm{H}$ angles that significantly deviate from linearity. The electronic (and geometric) situation for the series of complexes $\mathbf{3} \equiv \mathbf{E}$ is similar to $\mathbf{U}-\mathbf{O H}$ but more extreme and reminiscent to transition metal complexes with strongly (covalently) bound, terminal, closed-shell ligands. The bonding analysis in $\mathbf{3} \equiv \mathbf{E}$ clearly reveals $\mathrm{U} \equiv \mathrm{E}$ triple bonds, composed of one $\sigma$ and two $\pi$ bonds. These complexes feature $U$ ions almost in-plane with the aryloxide chelate (e.g. $U_{\text {oop }}-$ $0.08 \AA$ for $\mathbf{3} \equiv \mathbf{0})$. The small $\mathrm{U}_{\text {oop }}$ maximizes $\mathrm{U} \equiv \mathrm{E}$ orbital overlap, which leads to the shortest $\mathrm{U}-\mathrm{E}$ bond distances for the respective chalcogenide. In $\mathbf{3} \equiv \mathbf{E}$, the trans influence is the strongest, with $\mathrm{U}-\mathrm{N}_{\text {tacn }}$ distances getting close to $3 \AA$ (for $\mathbf{3} \equiv \mathbf{0}$ ).

\section{Conflicts of interest}

There are no conflicts of interest to declare.

\section{Acknowledgements}

This work was supported by funds of the Joint DFG-ANR projects (ME1754/7-1, ANR-14-CE35-0004-01), the German Federal Ministry of Education and Research (BMBF 2020+ support codes 02NUK012C and 02NUK020C); Clusterprojekt "MANGAN" support code 03SF0502) as well as the FAU Erlangen-Nürnberg.

\section{Notes and references}

1 Chianelli, R. R.; Pecoraro, T. A.; Halbert, T. R.; Pan, W. H.; Stiefel, E. I., J. Catal. 1984, 86, 226-230.

2 Angelici, R. J., Acc. Chem. Res. 1988, 21, 387-394.

3 DuBois, M. R., Chem. Rev. 1989, 89, 1-9.

4 Di Vaira, M.; Peruzzini, M.; Stoppioni, P., Inorg. Chem. 1991, 30, 1001-1007.

5 Sánchez-Delgado, R. A., J. Mol. Catal. 1994, 86, 287-307.

6 Hille, R., Chem. Rev. 1996, 96, 2757-2816.

7 Curtis, M. D.; Druker, S. H., J. Am. Chem. Soc. 1997, 119, 10271036.

8 Bianchini, C.; Meli, A., Acc. Chem. Res. 1998, 31, 109-116.

9 Hensen, E. J. M.; Lardinois, G. M. H. J.; de Beer, V. H. J.; van Veen, J. A. R.; van Santen, R. A., J. Catal. 1999, 187, 95-108.

10 Kuwata, S.; Hidai, M., Coord. Chem. Rev. 2001, 213, 211-305.

11 Matthews, R. G., Acc. Chem. Res. 2001, 34, 681-689.

12 Parkin, G., Chem. Rev. 2004, 104, 699-768.

13 Ibrahim, M. M.; Seebacher, J.; Steinfeld, G.; Vahrenkamp, H., Inorg. Chem. 2005, 44, 8531-8538.

14 Peruzzini, M.; Rios, I. D. L.; Romerosa, A., Coordination Chemistry of Transition Metals with Hydrogen Chalcogenide and Hydrochalcogenido Ligands. In Progress in Inorganic Chemistry, John Wiley \& Sons, Inc.: 2007; pp 169-453.

15 Li, L.; Rose, P.; Moore, P. K., Annu. Rev. Pharmacol. Toxicol. 2011, 51, 169-187.

16 Diamond, R. M.; Street, K.; Seaborg, G. T., J. Am. Chem. Soc. 1954, 76, 1461-1469.

17 Jensen, M. P.; Bond, A. H., J. Am. Chem. Soc. 2002, 124, 98709877.

18 Roger, M.; Barros, N.; Arliguie, T.; Thuéry, P.; Maron, L.; Ephritikhine, M., J. Am. Chem. Soc. 2006, 128, 8790-8802.

19 Dam, H. H.; Reinhoudt, D. N.; Verboom, W., Chem. Soc. Rev. 2007, 36, 367-377.

20 Gaunt, A. J.; Reilly, S. D.; Enriquez, A. E.; Scott, B. L.; Ibers, J. A.; Sekar, P.; Ingram, K. I. M.; Kaltsoyannis, N.; Neu, M. P., Inorg. Chem. 2008, 47, 29-41.
21 Brown, J. L.; Fortier, S.; Wu, G.; Kaltsoyannis, N.; Hayton, T. W., J. Am. Chem. Soc. 2013, 135, 5352-5.

22 Franke, S. M.; Rosenzweig, M. W.; Heinemann, F. W.; Meyer, K., Chem. Sci. 2015, 6, 275-282.

23 Andrez, J.; Pecaut, J.; Scopelliti, R.; Kefalidis, C. E.; Maron, L.; Rosenzweig, M. W.; Meyer, K.; Mazzanti, M., Chem. Sci. 2016, 7, 5846-5856.

24 Rosenzweig, M. W.; Scheurer, A.; Lamsfus, C. A.; Heinemann, F. W.; Maron, L.; Andrez, J.; Mazzanti, M.; Meyer, K., Chem. Sci. 2016, 7, 5857-5866.

25 Lu, E.; Cooper, O. J.; Tuna, F.; Wooles, A. J.; Kaltsoyannis, N.; Liddle, S. T., Chem. Eur. J. 2016, 22, 11559-11563.

26 Gregson, M.; Lu, E.; Tuna, F.; Mclnnes, E. J. L.; Hennig, C.; Scheinost, A. C.; McMaster, J.; Lewis, W.; Blake, A. J.; Kerridge, A.; Liddle, S. T., Chem. Sci. 2016, 7, 3286-3297.

27 Gregson, M.; Wooles, A. J.; Cooper, O. J.; Liddle, S. T., Comments Inorg. Chem. 2015, 35, 262-294.

28 Lu, E.; Cooper, O. J.; McMaster, J.; Tuna, F.; McInnes, E. J. L.; Lewis, W.; Blake, A. J.; Liddle, S. T., Angew. Chem. Int. Ed. 2014, 53, 6696-6700.

29 Cooper, O. J.; Mills, D. P.; McMaster, J.; Tuna, F.; Mclnnes, E. J. L.; Lewis, W.; Blake, A. J.; Liddle, S. T., Chem. Eur. J. 2013, 19, 7071-7083.

30 Mills, D. P.; Cooper, O. J.; Tuna, F.; Mclnnes, E. J. L.; Davies, E. S.; McMaster, J.; Moro, F.; Lewis, W.; Blake, A. J.; Liddle, S. T. J. Am. Chem. Soc. 2012, 134, 10047-10054.

31 Gardner, B. M.; Balazs, G.; Scheer, M.; Tuna, F.; McInnes, E. J.; McMaster, J.; Lewis, W.; Blake, A. J.; Liddle, S. T., Angew. Chem. Int. Ed. 2014, 53, 4484-4488.

32 Gardner, B. M.; Tuna, F.; Mclnnes, E. J.; McMaster, J.; Lewis, W.; Blake, A. J.; Liddle, S. T., Angew. Chem. Int. Ed. 2015, 54 7068-7072.

33 Gardner, B. M.; Balazs, G.; Scheer, M.; Wooles, A. J.; Tuna, F.; Mclnnes, E. J.; McMaster, J.; Lewis, W.; Blake, A. J.; Liddle, S. T., Angew. Chem. Int. Ed. 2015, 54, 15250-15254.

34 Gardner, B. M.; Balazs, G.; Scheer, M.; Tuna, F.; Mclnnes, E. J.; McMaster, J.; Lewis, W.; Blake, A. J.; Liddle, S. T., Nat. Chem. 2015, 7, 582-590.

35 Brown, J. L.; Fortier, S.; Lewis, R. A.; Wu, G.; Hayton, T. W., J. Am. Chem. Soc. 2012, 134, 15468-15475.

36 Smiles, D. E.; Wu, G.; Hayton, T. W., Inorg. Chem. 2014, 53, 12683-12685.

37 Smiles, D. E.; Wu, G.; Hayton, T. W., J. Am. Chem. Soc. 2014, 136, 96-99.

38 Ephritikhine, M., Coord. Chem. Rev. 2016, 319, 35-62.

39 Smiles, D. E.; Wu, G.; Hayton, T. W., Inorg. Chem. 2014, 53, 10240-10247.

40 King, D. M.; Liddle, S. T., Coord. Chem. Rev. 2014, 266-267, 2 15.

41 King, D. M.; McMaster, J.; Tuna, F.; Mclnnes, E. J. L.; Lewis, W.; Blake, A. J.; Liddle, S. T., J. Am. Chem. Soc. 2014, 136, 56195622.

42 King, D. M.; Tuna, F.; McInnes, E. J.; McMaster, J.; Lewis, W.; Blake, A. J.; Liddle, S. T., Science 2012, 337, 717-720.

43 Lam, O. P.; Heinemann, F. W.; Meyer, K., Chem. Sci. 2011, 2, 1538-1547.

44 Franke, S. M.; Heinemann, F. W.; Meyer, K., Chem. Sci. 2014 5, 942-950.

45 Liddle, S. T., Angew. Chem. Int. Ed. 2015, 54, 8604-8641.

46 Castro-Rodriguez, I.; Nakai, H.; Zakharov, L. N.; Rheingold, A. L.; Meyer, K., Science 2004, 305, 1757-1759.

47 Halter, D. P.; Heinemann, F. W.; Bachmann, J.; Meyer, K., Nature 2016, 530, 317-321.

48 Shannon, R., Acta Cryst. A 1976, 32, 751-767.

49 Straka, M.; Patzschke, M.; Pyykkö, P., Theor. Chem. Acc. 2003 109, 332-340.

50 Steffey, B. C.; Fanwick, P. E.; Rothwell I. P., Polyhedron 1990, 9, 963-968. 
51 Howard, W. A.; Trnka, T. M.; Parkin, G., Inorg. Chem., 1995, 34, 5900-5909.

52 Russo, M. R.; Kaltsoyannis, N.; Sella, A., Chem. Commun., 2002, 20, $2458-2459$.

53 Pauling, L., The Nature of the Chemical Bond, 3rd edn., Cornell University Press, Rochester, 1960.

54 Coulson, C. A.; Valence, 2nd edn., Oxford University Press, Oxford, 1961.

55 Castro-Rodriguez, I.; Meyer, K., Chem. Commun. 2006, 13, 1353-1368.

56 Castro-Rodriguez, I.; Olsen, K.; Gantzel, P.; Meyer, K., Chem. Commun. 2002, 23, 2764-2765.

57 Bart, S. C.; Anthon, C.; Heinemann, F. W.; Bill, E.; Edelstein, N. M.; Meyer, K., J. Am. Chem. Soc. 2008, 130, 12536-12546.

58 Schmidt, A. C.; Heinemann, F. W.; Lukens, W. W., Jr.; Meyer, K., J. Am. Chem. Soc. 2014, 136, 11980-11993.

59 King, D. M.; Tuna, F.; McInnes, E. J. L.; McMaster, J.; Lewis, W.; Blake, A. J.; Liddle, S. T.; Nat. Chem., 2013, 5, 422-488

60 Pyykkö, P.; J. Phys. Chem. A, 2015, 119, 2326-2337.

61 Fortier, S.; Brown, J. L.; Kaltsoyannis, N.; Wu, G.; Hayton, T. W., Inorg. Chem. 2012, 51, 1625-1633.

62 Hoerger, C. J.; La Pierre, H. S.; Maron, L.; Scheurer, A.; Heinemann, F. W.; Meyer, K., Chem. Commun. 2016, 52, 10854-10857.

63 Kosog, B.; La Pierre, H. S.; Heinemann, F. W.; Liddle, S. T.; Meyer, K., J. Am. Chem. Soc. 2012, 134, 5284-5289.

64 Kraft, S. J.; Walensky, J.; Fanwick, P. E.; Hall, M. B.; Bart, S. C., Inorg. Chem. 2010, 49, 7620-7622.

65 Ventelon, L.; Lescop, C.; Arliguie, T.; Ephritikhine, M.; C. Leverd, P.; Lance, M.; Nierlich, M., Chem. Commun. 1999, 7, 659-660.

66 Castro-Rodriguez, I.; Olsen, K.; Gantzel, P.; Meyer, K., J. Am. Chem. Soc. 2003, 125, 4565-4571.

67 Castro-Rodriguez, I.; Nakai, H.; Gantzel, P.; Zakharov, L. N.; Rheingold, A. L.; Meyer, K., J. Am. Chem. Soc. 2003, 125, 15734-15735.

68 Howard, W. A.; Parkin, G., J. Am. Chem. Soc. 1994, 116, 606615.

69 Nakamoto, K., Theory of Normal Vibrations. In Infrared and Raman Spectra of Inorganic and Coordination Compounds, John Wiley \& Sons, Inc.: 2008; pp 1-147.

70 Arney, D. S. J.; Burns, C. J., J. Am. Chem. Soc. 1995, 117, 94489460.

71 Zi, G.; Jia, L.; Werkema, E. L.; Walter, M. D.; Gottfriedsen, J. P.; Andersen, R. A., Organometallics 2005, 24, 4251-4264.

72 Kindra, D. R.; Evans, W. J., Chem. Rev. 2014, 114, 8865-8882.

73 Ohwada, K., J. Inorg. Nucl. Chem., 1976, 38, 741-745.

74 Halter, D. P.; La Pierre, H. S.; Heinemann, F. W.; Meyer, K., Inorg. Chem. 2014, 53, 8418-8424.

75 Barros, N.; Maynau, D.; Maron, L.; Eisenstein, O.; Zi, G.; Andersen, R. A., Organometallics 2007, 26, 5059-5065.

76 La Pierre, H. S.; Meyer, K., Activation of Small Molecules by Molecular Uranium Complexes. In Progress in Inorganic Chemistry Volume 58, John Wiley \& Sons, Inc.: 2014; pp 303416. 